MATEC Web of Conferences 19,01007 (2014)

DOI: $10.1051 /$ matecconf/ 20141901007

C) Owned by the authors, published by EDP Sciences, 2014

\title{
Superheater tube element temperature regime
}

\author{
Vladimir S. Loginov and Azad T. Parpiev ${ }^{1}$ \\ National Research Tomsk Polytechnic University, 30, Lenin Avenue, 634050 Tomsk, Russia
}

\begin{abstract}
Physico-mathematical model for equation of non-stationary temperature conditions of superheater are defined in this work. This model can be used for calculation of temperature regime for both clean surface tube and tube with pollution on its outer and inner surface. Validation of numerical results, which were taken during calculation, are made. Numerical results were compared with results of thermalphysic calculation and results obtained by other authors. Error of numerical results is not more than $2 \%$.
\end{abstract}

\section{Introduction}

Superheaters are operated in the hardest conditions in comparison with other heating surfaces [1]. Therefore, study of thermal processes of steam generator superheater is an urgent problem of heatand-power engineering sector nowadays. It should be noted that experimental method, thermalphysic and hydraulic calculations are the basic methods for investigation of superheater damages [1], [2]. However, these methods have their typical disadvantages. The experimental method requires certain equipment and great financial expenditure while results of thermalphysic and hydraulic calculations are inaccurate. Thereby, application of numerical modeling method is the most rational method in this case.

Results, presented in this paper, have been obtained during physical and mathematical model's computation of temperature conditions of superheater tube with clean surface and with pollution on its outer and inner surface.

Research novelty of this study is in formulation of physical-mathematical model of superheater tube's temperature conditions with pollution on its outer and inner surface, according to the physics of thermal processes, occurring on this heating surface, and check of results validity.

Practical significance of this study is a possibility of this physical and mathematical model application for calculation of unsteady operation modes of steam generator superheater.

\section{Problem statement}

A diagram of prototype system is given in the Figure 1. The prototype system is a cylindrical wall of tube of the steam generator BKZ-75-39 superheater. Distributions of temperature on the cylindrical

\footnotetext{
${ }^{\mathrm{a}}$ Corresponding author: azatparpiev@mail.ru
} 
wall with outer and inner pollution are determined using the system of two-dimensional nonstationary heat conduction equations. Boundary temperatures of the first (scale crust layer), second (cylindrical wall) and third (soot layer) zones are found by boundary conditions of the first, third and fourth type, respectively (1).

Thermal physic properties of cylindrical wall, scale crust and soot are known values [3]. Input data are taken from the steam generator certificate. Calculation algorithm is known [4]. The following basic assumptions are made for the problem statement:

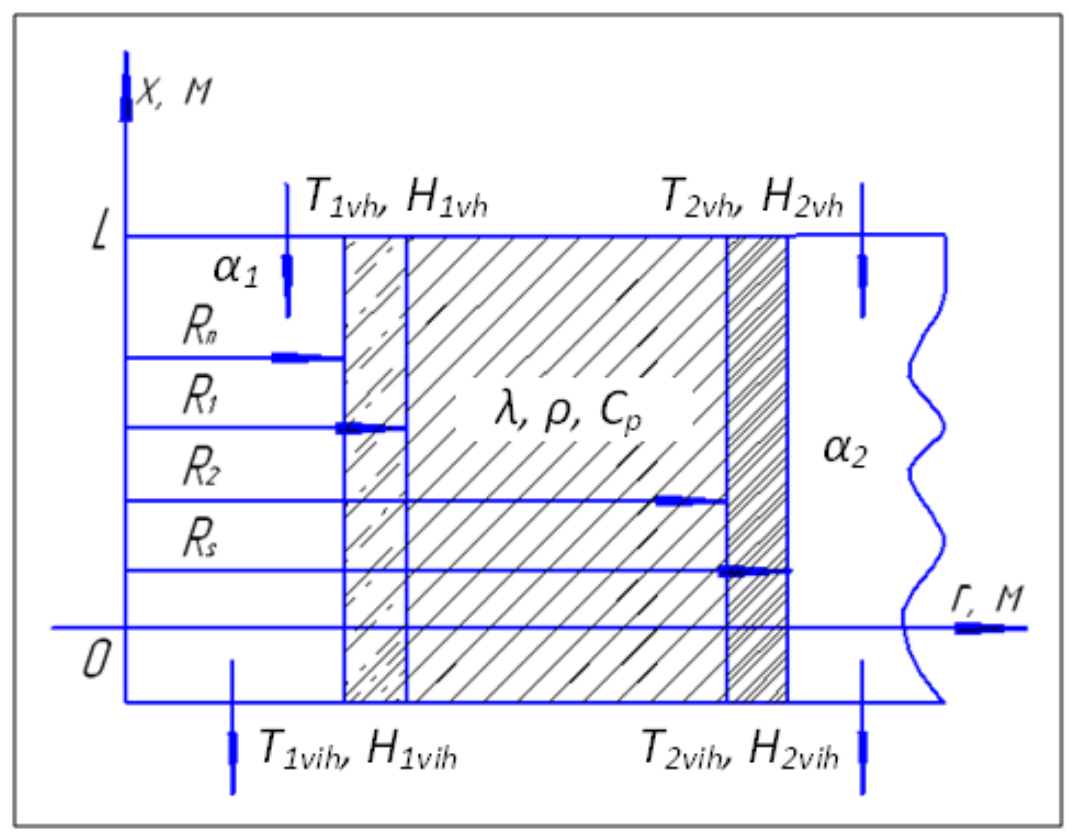

Figure. 1. Diagram of a cylindrical wall of the superheater polluted tube

1. Thermalphysic properties of smoke fumes, tube surface material, steam and pollutions are constants.

2. Both smoke fumes and steam are considered to be incompressible media. Friction heat can be neglected.

3. Straight, round and vertical element of superheater coil tube with certain geometric features and without internal defects in the crystal lattice is studied in this paper.

4. This tube element is washed by hydrodynamically and thermally stable flows on its outer and inner surfaces. Therefore, average values of heat-transfer coefficients and temperatures of smoke fumes and steam are taken for the tube element under study.

Temperature regime of cylindrical surface of clean tube is investigated as a particular case in this paper.

The obvious difference scheme is used for this problem solving, as this scheme is applicable in our case [5], [6]. 


\section{Mathematical model}

Temperature regime of the polluted coil tube element is determined by the mathematical model with initial and boundary conditions, given below (1). The mathematical model, used for this case solution, is also given below (2).

$C_{p 1}, C_{p 2}, C_{p 3}$ are heat capacities of scale crust, steel and soot in these mathematical models, respectively. The benchmark unit of heat capacity is joule per kilogram per Celsius degree. $\rho_{1}, \rho_{2}, \rho_{3}$ are densities of scale crust, steel and soot respectively, measured in kilograms per cubic meter. $\lambda_{1}, \lambda_{2}$, $\lambda_{3}$ are heat conductivity coefficients of scale crust, steel and soot, measured in watt per meter per Celsius degree. $\alpha_{1}, \alpha_{2}$ are heat-transfer coefficient of scale crust, steel and soot, which is measured in watt per square meter per Celsius degree. $T_{c 1}, T_{c 2}$ are average temperature of smoke fumes and stem, measured in Celsius degrees. $T_{1}, T_{2}$ are average temperature of outer and inner surfaces. The benchmark unit of this quantity is Celsius degree too.

$$
\begin{aligned}
& C_{p 1} \rho_{1} \frac{\partial T_{1}}{\partial \tau}=\lambda_{1}\left(\frac{\partial^{2} T_{1}}{\partial r^{2}}+\frac{1}{r} \frac{\partial T_{1}}{\partial r}+\frac{\partial^{2} T_{1}}{\partial x^{2}}\right) ; \tau>0, r_{1}<r<r_{2}, 0<x<l ; \\
& C_{p 2} \rho_{2} \frac{\partial T_{2}}{\partial \tau}=\lambda_{2}\left(\frac{\partial^{2} T_{2}}{\partial r^{2}}+\frac{1}{r} \frac{\partial T_{2}}{\partial r}+\frac{\partial^{2} T_{2}}{\partial x^{2}}\right) ; \tau>0, r_{2}<r<r_{3}, 0<x<l \text {; } \\
& C_{p 3} \rho_{3} \frac{\partial T_{3}}{\partial \tau}=\lambda_{3}\left(\frac{\partial^{2} T_{3}}{\partial r^{2}}+\frac{1}{r} \frac{\partial T_{3}}{\partial r}+\frac{\partial^{2} T_{3}}{\partial x^{2}}\right) ; \tau>0, r_{3}<r<r_{4}, 0<x<l ; \\
& \tau=0, T_{i}(0, r, x)=T_{H i} ; i=1,2,3 \text {; } \\
& r=r_{1},-\lambda_{1} \frac{\partial T_{1}\left(\tau, r_{1}, x\right)}{\partial r}=\alpha_{1}\left[T_{c 1}-T_{1}\left(\tau, r_{1}, x\right)\right] \\
& r=r_{2}, \lambda_{1} \frac{\partial T_{1}\left(\tau, r_{2}, x\right)}{\partial r}=\lambda_{2} \frac{\partial T_{2}\left(\tau, r_{2}, x\right)}{\partial r}, T_{1}\left(\tau, r_{2}, x\right)=T_{2}\left(\tau, r_{2}, x\right) \\
& r=r_{3}, \lambda_{2} \frac{\partial T_{2}\left(\tau, r_{3}, x\right)}{\partial r}=\lambda_{3} \frac{\partial T_{3}\left(\tau, r_{3}, x\right)}{\partial r}, T_{2}\left(\tau, r_{3}, x\right)=T_{3}\left(\tau, r_{3}, x\right) \\
& r=r_{4},-\lambda_{3} \frac{\partial T_{3}\left(\tau, r_{4}, x\right)}{\partial r}=\alpha_{2}\left[T_{c 2}-T_{3}\left(\tau, r_{4}, x\right)\right] ; \\
& x=0, T_{i}(\tau, r, 0)=T_{1}=\text { const }, i=1,2,3 ; x=l, T_{i}(\tau, r, l)=T_{2}=\text { const } ; i=1,2,3 \text {. } \\
& C_{p 2} \rho_{2} \frac{\partial T_{2}}{\partial \tau}=\lambda_{2}\left(\frac{\partial^{2} T_{2}}{\partial r^{2}}+\frac{1}{r} \frac{\partial T_{2}}{\partial r}+\frac{\partial^{2} T_{2}}{\partial x^{2}}\right) ; \tau>0, r_{3}<r<r_{4}, 0<x<l ; \\
& \tau=0 ; T_{2}(0, r, x)=T_{H 2} ; \\
& r=r_{3},-\lambda_{2} \frac{\partial T_{2}\left(\tau, r_{3}, x\right)}{\partial r}=\alpha_{1}\left[T_{c 1}-T_{2}\left(\tau, r_{3}, x\right)\right] \text {; } \\
& r=r_{4},-\lambda_{2} \frac{\partial T_{2}\left(\tau, r_{4}, x\right)}{\partial r}=\alpha_{2}\left[T_{c 2}-T_{2}\left(\tau, r_{4}, x\right)\right] ; \\
& x=0 ; T_{1}(\tau, r, 0)=T_{1}=\text { const } \text {; } \\
& x=0 ; T_{2}(\tau, r, 0)=T_{2}=\text { const } .
\end{aligned}
$$

Thermalphysic calculation of steady regime is used for validity check of obtained results in the problem statement. Also, these results are compared with other results from similar problems solving by other authors [7], [8]. 


\section{MATEC Web of Conferences}

\section{Results}

The results, obtained according to the method of finite differences and thermalphysic calculation, are given below in Figures 2 and 3 and in Table 1.
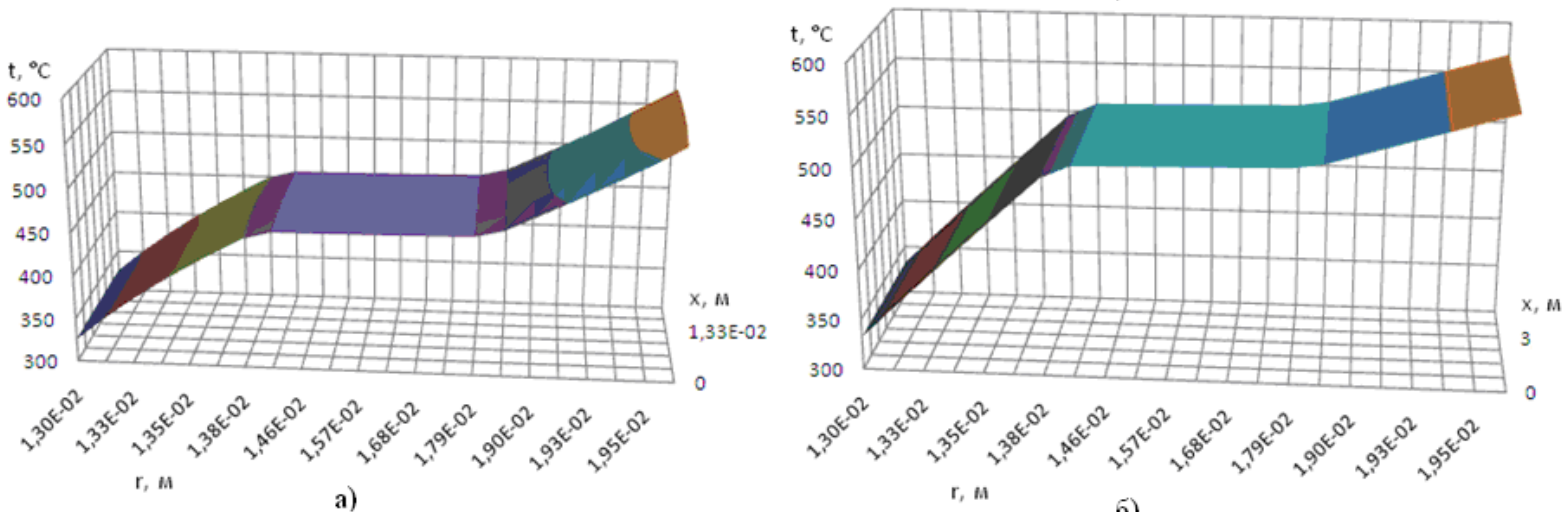

a)

б)

Figure. 2. Temperature field on a cylindrical wall of superheater polluted tube at the lengths of 0.02 and $3 \mathrm{~m}$
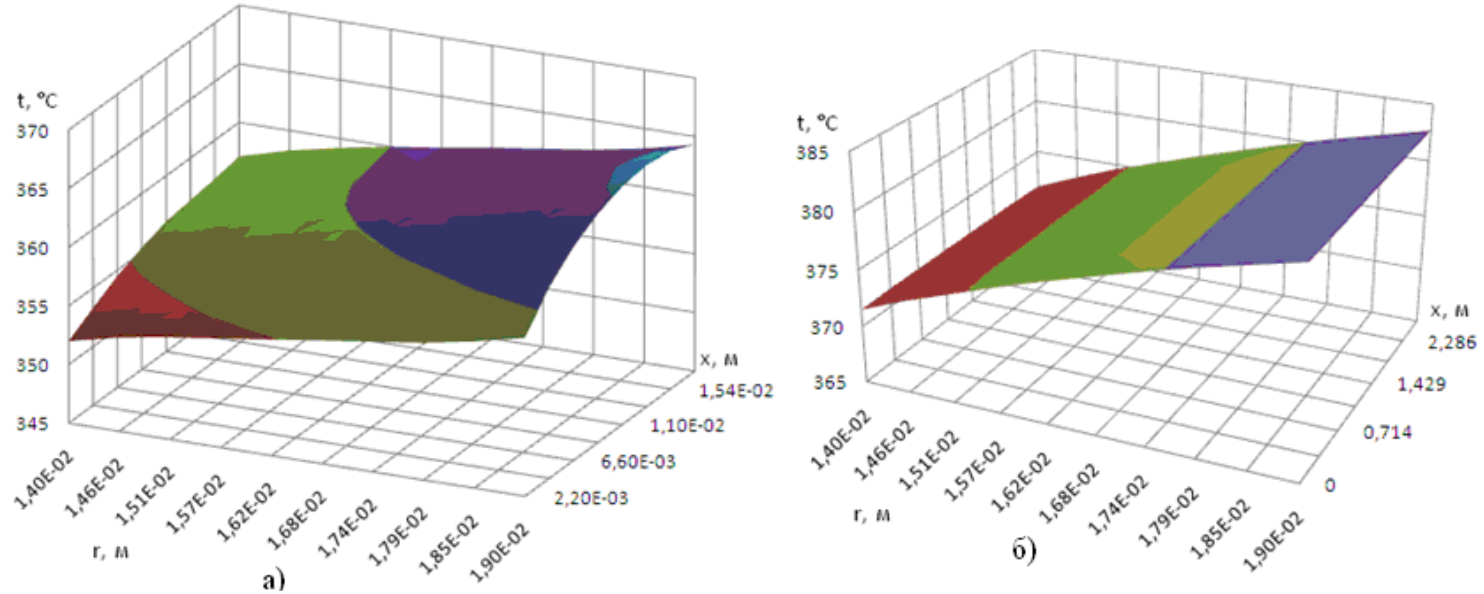

Figure. 3. Temperature field on a cylindrical wall of superheater clean tube at the lengths of 0.02 and $3 \mathrm{~m}$

Table 1

\begin{tabular}{|c|c|c|c|c|c|c|c|c|}
\hline $\begin{array}{c}\text { Length, } \\
\mathrm{m}\end{array}$ & \multicolumn{4}{|c|}{$\begin{array}{l}\text { Average surface temperatures, according } \\
\text { to the method of finite differences, }{ }^{\circ} \mathrm{C}\end{array}$} & \multicolumn{4}{|c|}{$\begin{array}{l}\text { Average surface temperature, according to } \\
\text { the thermalphysic calculation, }{ }^{\circ} \mathrm{C}\end{array}$} \\
\hline \multicolumn{9}{|c|}{ For a polluted tube element } \\
\hline & $T_{\text {S.c }}$ & $T_{s 2}$ & $T_{s 1}$ & $T_{s}$ & $T_{\text {s.c }}$ & $T_{s 2}$ & $T_{s l}$ & $T_{s}$ \\
\hline 0,2 & 326 & 507 & 509 & 557 & 329 & 509 & 513 & 560 \\
\hline 3 & 328 & 509 & 512 & 558 & 331 & 509 & 512 & 559 \\
\hline \multicolumn{9}{|c|}{ For a clean tube element } \\
\hline & \multicolumn{2}{|c|}{$\mathrm{t}_{\mathrm{s} 2}$} & \multicolumn{2}{|c|}{$t_{s 1}$} & \multicolumn{2}{|c|}{$\mathrm{t}_{\mathrm{s} 2}$} & \multicolumn{2}{|c|}{$t_{s 1}$} \\
\hline 0,02 & \multicolumn{2}{|c|}{358} & \multicolumn{2}{|c|}{364} & \multicolumn{2}{|c|}{359} & \multicolumn{2}{|c|}{365} \\
\hline 3 & \multicolumn{2}{|c|}{373} & \multicolumn{2}{|c|}{379} & \multicolumn{2}{|c|}{374} & \multicolumn{2}{|c|}{383} \\
\hline
\end{tabular}


$T_{s 1}, T_{s 2}$ are average outer and inner surface temperatures in Table 1. $\mathrm{t}_{\mathrm{s.c}}, \mathrm{t}_{\mathrm{s}}$ are scale crust and soot temperatures. It's easy to see that temperature values, obtained by thermal calculation, don't differ almost from numeric results.

\section{Conclusions}

The following results were obtained:

1. Physico-mathematical model, formulated in this paper, is applicable to determine the temperature regime of a superheater tube, as calculating error is not more than $1 \%$, according to the method of finite differences and thermalphysical calculation

2. This physico-mathematical model will further be used to determine non-stationary modes for superheaters.

The reported study was supported by the State Contract 14.740.11.0101.

\section{References}

1. V.V. Artamonov, Control. Diagnostics 1, 8-11 (2010).

2. V.A. Bogachev, O.Ye. Taran, Electric power stations 1, 14-17 (2006).

3. A.F. Chudnovskiy, Teplofizicheskie svoystva dispersnih materialov (Thermalphysic properties of particulates) (State Publishing House of physico-mathematical literature, Moscow, 1962).

4. A.R.Dorohov, A.S. Zavorin, A.M. Kazanov, V.S. Loginov, Modelirovanie teplovidelyayushih sistem (Modelling of heat-generating complexes) (Publishing House of scientific technical literature, Tomsk, 2000).

5. A.R.Mitchell, D.F. Griffiths, The Finite Difference Method in Partial Differential Equations, (Chichester, Wiley, 1980).

6. A.A. Samarskiy, Teoriya raznostnih shem (Theory of difference schemes) (Science, Moscow, 1977).

7. Teplovoy raschet kotlov. Normativniy metod (Thermal design of boilers. Normative document) (Saint-Petersburg, 1998).

8. Yu.M. Lipov, Yu.F. Samoylov, T.V. Vilenskiy, Komponovka i teplovoy rashet parovogo kotla (Construction and thermal design of boiler) (Energoatomizdat, Moscow, 1988). 